\title{
Un tipo iconográfico de Hércules en Occidente
}

\author{
Javier Burgaleta Mezo *
}

El estudio de algunos de los tipos iconográficos con los que se representa a Hércules en Occidente resulta esencialmente incompleto si no se incardina y enraiza con lo que representa, desde el punto de vista figurativo y cultural, en un ámbito más amplio intermediterráneo. Esto quiere decir que a la hora de interpretar algunas figuras marginales respecto a aquellas otras creadas en los núcleos donde se dan los principales desarrollos iconográficos, deberemos tomar en consideración otros muchos elementos que normalmente no se tienen en cuenta al estudiar esas zonas nucleares del clasicismo.

En efecto, la exégesis de ciertos tipos "marginales" es todavía oscura en muchos sentidos, y hay que recurrir a un análisis alternativo y global, a nuevas vias que nos ayuden a comprender la naturaleza de las piezas y la de su contexto. Ello ha de conducir ineludiblemente a plantear lo que fue el fenómeno de la recepción y el impacto de la potente iconografía greco-romana en algunas de las regiones que, de diferentes maneras, entran en contacto con ella, y a cuestionarse, a la vez, el papel que lo indígena juega en la interpretación de esas formas y de los conceptos culturales implícitos en ellos. Pero al aducir un marco de influencias, no nos podemos limitar a las existentes en la última parte del I milenio. Hay que recalcar la importancia del Mediterráneo como vía de contactos, y la antigüedad de las relaciones que a través de él se habian establecido entre sus orillas, remontándola hasta la edad del Bronce. En efecto, hay que tener en cuenta la existencia de diferentes sustratos a

* Departamento de Prehistoria e Historia Antigua, UNED, Madrid. 
partir de los cuales se elabora un entramado de relaciones que puede volver a surgir en diferentes manifestaciones, pero que a menudo son difícilmente observables debido a la escueta información que poseemos para épocas oscuras o remotas. La misma cultura griega, que en su momento será un foco de creación de impulsos dominantes que se reflejarán en todo el ámbito mediterráneo, es producto, a su vez, de una síntesis en la que ese mismo nexo mediterráneo también jugó un papel destacado, en este caso, transmitiendo influjos provenientes preferentemente de Oriente. Pero en épocas muy anteriores, participó de alguna manera, quizás en competencia con otros grupos, en la creación de esa red de contactos.

Heracles-Hércules, en su complejidad, presenta rasgos que deben tenerse en cuenta en este caso, como es su antigüedad ${ }^{1}$, y su ubicuidad, que le caracteriza ya en los diferentes viajes que realiza en sus trabajos, tal como los presenta su mito, en los que jalona las rutas del descubrimiento del mundo para los griegos. Además, absorbe mitos y figuras locales que se pueden integrar de alguna manera en su leyenda, realizada por escritores clásicos, o interpretada en cada lugar, confundida simplemente con las leyendas y cultos preexistentes.

Desde estas coordenadas, habrá que valorar el peso específico de esas componentes en cada región, $y$, al mismo tiempo, dentro de un marco cultural más general y amplio, con el fin de delimitar que se debe a la propia originalidad de cada cultura, o a la asimilación de influencias exteriores, y como éstas se particularizan al contacto con un poso local, dado por unas circunstancias, entorno y modos de vida. Ambos componentes entran en una relación dialéctica particular en cada caso, conviviendo o adaptándose unas a otras según el ámbito cultural en que se produzcan.

Uno de esos tipos iconográficos de Hércules de contenido confuso es un conjunto de figurillas exentas, en bronce, de pequeñas dimensiones (entre 8 y $15 \circ 20 \mathrm{cms}$. por término medio), y conocidos como Hércules "promachos" o combatiente. Proceden de Italia, pero también se han encontrado en distintos puntos de Francia y Gran Bretaña, y han sido recopiladas por G. Colonna en Italia y S. Boucher en Francia (CoIonna, C., 1970; Boucher, S., 1976). Balty les ha dedicado su atención

' $E$ incluso, el punto hasta el que se puede remontar la figura de Heracles en la cultura helénica (cf. Kirk, 1974, ed. esp. 1984, pág. 147, y de Nilsson, citado en el anterior, lo que podría relacionarse, atrevidamente, con la consistencia y el carácter de los contactos egeos y micénico-egeos en el Mediterráneo occidental e incluso en la Europa interior). 
en diferentes trabajos (son innumerables los investigadores que las han ido tratando en diferentes obras e inventarios), y a él nos remitimos para la descripción del tipo, que en esencia representa a un hombre desnudo, con el pie izquierdo generalmente adelantado, el brazo derecho en alto y el codo doblado, en actitud de ir a descargar un golpe. En la mayoría de las figuritas la maza ha desaparecido. Este esquema de movimiento es el mismo que encontramos en decenas de figuras semejantes a estas y procedentes también de Italia, que representan a "Marte" y "Minerva" (Colonna 1970) (para Richardson, 1983, lams. 135-146, "guerreros" sin más) en algunos casos con una lanza que todavía se conserva, y pequeñas variaciones en aspectos secundarios -generalmente cubiertos con cascos de cimera y alto penacho, y con armaduras de marcado sabor griego-. Alguno de los mencionados "guerreros" de Richardson embraza incluso un escudo, e idéntico movimiento tienen unos «lanzadores de jabalina". Entre todas estas piezas emparentadas, parece por tanto, algo señalable como particular de la península. No es, sin embargo, privativo de este mundo itálico, pues, como veremos luego, lo encontramos también en el levante mediterráneo, en Canaán, con fechas que se remontan al segundo milenio.

Por su distribución, aspecto y tipo, parece que su existencia va ligada a un ambiente puramente itálico indígena, relativamente marginal respecto a lo greco-romano, en el que queda por resolver el papel de lo etrusco ${ }^{2}$. Aparte de las cuestiones de su evolución morfológica dentro de la península itálica, intentos de ordenación tipológica basados en pequeños detalles, referencias a talleres, etc., que vamos a evitar, formalmente, es un grupo con personalidad propia que está lejos de las representaciones de estilo helenístico, en las que la elaboración de la figura humana sigue los pasos dados por la estatuaria mayor, con un detalle cuidado por la anatomía y buscando una reproducción lo más fiel posible de la realidad. Estas por el contrario, son de notable esquematismo, aunque no por ello dejan de marcar redundantemente ciertos detalles.

Tanto Balty como luego G. Colonna parecen coincidir en fecharlas entre los siglos IV y II-I a. C., pudiendo remontarse algunas hasta el siglo $\mathrm{V}^{3}$. Para Bayet, esta categoria nace hacia el final del siglo $\mathrm{V}$ a. $\mathrm{C}$.,

2 S. BOUCHER (1976, pág. 30) piensa que todas ellas revelan de una u otra manera el arte etrusco, en este sentido, R. GAVELLE (1967, pág. 133), expone las opiniones en favor $y$ en contra, entre otras, la de J. BaYet (1926, pág. 39), que ve en el tipo "du lac Fucin" un origen más local, frente a otro chipriota.

${ }^{3}$ La mayoría de ellos, según BaLTY (1962, pág. 203, nota 3, y cont. pág. 204), serían de los siglos III a I a.C. 
suplantada claramente por otro tipo desde el siglo II, en un momento en el que la civilización itálica tiende a unificarse ${ }^{4}$ y subsistirá sin cambios en la Italia romana. Según R. Gavelle, (1967, pág. 134), la fecha de estos pequeños bronces plantea complicados problemas, y «la datación tardía de ciertos ejemplares arcaizantes está fuera de duda" ${ }^{5}$.

Para S. Boucher, que acepta las conclusiones propuestas por Balty y G. Colonna, estos bronces se habrían introducido en la Galia en el siglo IV o a finales del $\mathrm{V}$, y su distribución, coincidente con la de otra serie de bronces en el Macizo Central y rebordes occidentales de los Alpes, induciria a pensar en el uso de una vía continental, que uniría Italia con el norte de la Galia por los pasos suizos, y que sería una de las "vias del ámbar" ${ }^{6}$. Para ello sostiene la existencia de contactos múltiples entre el norte de Italia y sur de la Galia, hipótesis que vendrian a apoyar estos bronces. Pero, ¿qué hacen esas figurillas tan alejadas de su supuesto lugar de origen? Las importaciones de objetos manufacturados griegos, usados con carácter suntuario, está bien documentada en el interior de la Galia, y su presencia se justifica por si misma, en una sociedad con incipiente diferenciación social, subrayada por el uso restringido de objetos exóticos y valiosos. Pero estas estatuillas toscas no parece que guarden tal sentido, o, por lo menos, no exactamente. Queda por esclarecer esta cuestión.

Determinar la finalidad y el posible significado de estas figuras no es sencillo. A menudo no se señalan contextos claros. Pero la intuición de un aspecto votivo, que remite a un simbolismo mayor cuanto más acusado sea el esquematismo, resulta inmediata. R. Gavelle (1967, págs. 137 y y ss.) apunta que las figuras aparecidas en las regiones septentrionales se pueden relacionar con un culto militar a Hércules Victor ${ }^{7}$. Hay

4 Bayet, J., (1926, pág. 46 y págs. 48-49); sobre esto, v. J. Heurgon (1961, pág. 25).

5 La datación más tardía es obligada por la tesis de este autor, quien asocia estas figuras con el mundo imperial, sobre todo a través de ejemplares como el de Camboglanna, contextualizados en ambiente claramente romano, como se verá más abajo.

${ }^{6}$ En la tipologia que introduce seguidamente S. BOUCHER (1976, págs. 23, 24 y ss.), hay que distinguir entre los tipos “itálicos", especialmente el II, de Hércules combatiente, imberbe, con cabeza desnuda, frente al tercer tipo, de influencia griega; sobre las vías de contacto con Centroeuropa, cf. F. BENOIT, ( 1965, pág. 164); y CH. PICARD, 1960, págs. 409 y ss. S. Boucher, 1973, págs. 79 y ss.).

7 Y lo apoya en la figura descubierta en el "limes" británico, en Camboglanna. Discurre, además, sobre la causalidad de que se hubiese encontrado "posiblemente" en la proximidad de un granero, lo que evocaría el templo junto a la "Porta Trigemina", donde existía un mercado, o los depósitos de la Annonae, no lejanos del “Ara Maxima». Por eso no se decide por una datación cerrada de las figuras, puesto que podrían sobrevivir durante época imperial. 
que reconocer que la mayoría de las estatuillas recogidas por $\mathrm{G}$. Colonna tienen ese aspecto belicoso y que, por tanto, bien pudiera tratarse de representaciones de una clase de Hércules guerrero, quizás el mismo Hercules Víctor, aunque el tipo de Hércules "Víctor" que se encuentra en la iconografía clásica es otro, reposando, apoyado generalmente sobre la maza, y sosteniendo las manzanas de las Hespérides, una copa, o una corona en una mano.

Sin embargo, se da otra posibilidad: es la de Hércules como genio protector, en un papel ligado a lo personal. En ese sentido, se ha subrayado en diferentes sitios sus similitudes con el mismo primitivo papel que tuvo el Marte itálico, aspecto que, de alguna manera, trascendió a la Galia $^{8}$. Igualmente, puede tener relación con las aguas, como coinciden en indicar el mismo R. Gavelle, (1967, pág. 138), y S. Boucher (1976, pág. 33).

En lo referido al origen de este tipo de estatuillas, sobre todo en to que respecta al esquema de movimiento encontramos otro problema. Aún recalcando su carácter itálico ${ }^{9}$, resulta dificil excluir alguna clase de influencia helenizante de una figura tan esencialmente griega como Heracles-Hércules. Pero ise trata de una realización, de un "diseño" puramente local, sobre un culto a Hércules importado - como apunta J. Bayet (1926a) para el Hércules romano-, o superpuesto a otra figura anterior?. Desde luego es un grupo numeroso y consistente, esencialmente semejante, que se mantiene durante algunos siglos, y, quizás, perviva durante el imperio. No se puede negar su personalidad. Si lo comparamos con otras representaciones de Heracles-Hércules del mundo griego arcaico y clásico (Furtwängler, 1886-1890, col. 2135-2153 Dürrbach, F., 1900), aparte del caso chipriota y otros aislados, no parece haber un antecedente ni paralelo semejante.

Sin embargo, y como se dijo antes, se puede encontrar un paralelo iconográfico en el extremo oriental del Mediterráneo, cuya significatividad habrá que valorar. Son un tipo de estatuillas que forman un grupo muy homogéneo, de varones con idéntica posición que las figurillas itálicas, aunque tocados con tiaras (lo que es una notable diferencia), semejantes a la corona del Bajo Egipto, y cubiertos, a veces por un faldellin, que han sido recopiladas y estudiadas por Negbi (1976, p. 29 a 41 y 112 y y ss.)

${ }^{8}$ La misma S. Boucher (1976, pág. 33), así lo indica E. Thevenot (1955, pág. 143; pág. 149), y F. BENOIT (1959, pág. 129).

${ }^{9}$ En la iconografía está presente en elementos como la piel de león doblada sobre el brazo, se consideran un rasgo itálico que se encuentra también en la escultura mayor. 
y Seeden (1980). Estas figuras tienen una larga tradición, pues otras similares, también portando armas, se remontan a los inicios del Bronce Medio, pero este tipo último - Tipo III de Negbi- resulta ser la figura dominante desde finales de la Edad del Bronce, expandiéndose en el Bronce Final y Primera Edad del Hierro ampliamente por la cuenca del Mediterráneo. Según Negbi (id. p. 118), diferentes indicios hacen suponer que se trata del dios Adad Anat. Por otra parte, D. Collon (1972, pág. 131), plantea un origen indoeuropeo, aunque dentro del marco estrictamente oriental, en relación con un dios de las tormentas, creando los sirios el tipo figurado - tomado de la estatuaria egipcia, donde está presente desde el III milenio-, y lo pone en contacto con la figura de Melqart ${ }^{10}$.

En este sentido hay que señalar su presencia en el Mediterráneo occidental, como la figurilla de Sciacca, recuperada frente a la costa occidental de Sicilia, o la de los alrededores de la nouraga Flumenelongu, próxima a Alghero, en Cerdeña.

Sin embargo, queda por aclarar varios puntos sobre esta importación, especialmente a qué época se puede adscribir. D. Collon indicaba la relación entre estas figurillas y Melqart. Chiapisi (1961) se manifestaba en el mismo sentido, y les daba una fecha entre los siglos XII uXI a. C., poniéndola en relación con la presencia de los fenicios en Sicilia. Por el contrario, V. Tusa (1973, pág. 176), que también apoya esta fecha, señala, citando a A. M. Bisi (1968, pág. 1157 y ss.), la imposibilidad de asociarla con Melqart, que aparece en el Próximo Oriente tras la invasión de los Pueblos del Mar, y secunda la identificación con Hadad o Reshef. Pero disiente por completo con el resto del citado trabajo de la investigadora italiana. No cree que la estatuilla se pueda vincular con un transporte micénico. Su presencia en el Mediterráneo occidental vendría con lo fenicio, y para elio concede rebajar un poco la fecha hasta el siglo XII, aunque tipológicamente se pudiese subir un poco, dada la semejanza con ejemplares ugaríticos. En otro trabajo posterior, A. M. Bisi (1977-78) mantiene la vinculación con el mundo egeo de la Edad de Bronce para el hallazgo siciliano, mientras que en otros casos -ejemplar procedente de Alghero-, ve uno de los testimonios más antiguos de las relaciones entre nouragas y comerciantes del Próximo Oriente tras la caida del imperio micénico. Es decir, la posibilidad de que se puede remontar a las primeras navegaciones de pueblos orientales por el Mediterráneo, - pero

10 "The Tyrian god Melqart, represented in this way, is found wherever the Phoenicians or Carthaginians traded", y se remite a Dussaud, (1946-48, pág. 225). 
anteriores a la expansión fenicia- y trae a colación los talleres chipriotas que se supone elaborarían piezas semejantes.

La falta de acuerdo al respecto, obliga a ser cautos a la hora de afirmar a quién se debe atribuir la presencia de la figura en este área geográfica, o a que fenómeno hay que adscribirlo, y si es anterior o posterior al colapso del 1200 en el Próximo Oriente ${ }^{11 .}$

Llega el momento de preguntarse hasta qué punto el origen del tipo iconográfico itálico pudo estar en esta clase de figuras que se difunden hacia occidente. Aventurar una conexión entre unas y otras sin pasos intermedios documentados es excesivamente arriesgado (pues faltan los testimonios de una maduración del tipo en Italia, o una evaluación sosegada que permita afirmar tal cosa). Tendremos, de momento, que contentarnos con barajar hipótesis más o menos aventuradas, dentro de las muchas explicaciones que se podrían dar ${ }^{12}$.

Hay que tener en cuenta que, si por una parte, la presencia de lo fenicio es innegable en la península itálica -dentro de lo orientalizante${ }^{13}$, todas estas suposiciones tienen como premisa la escasa influencia que se supone a los impulsos griegos en la conformación de este tipo, apoyándose en el vacio de figuras semejantes entre la primitiva estatuaria griega continental ${ }^{14}$. Pero negar $u$ obviar sin más esta influencia plan-

"En cualquier caso, es interesante señalar como parecen existir figuras similares en el I milenio, nueva reinterpretación de prototipos egipcios, documentados en distintos puntos del Mediterráneo. La misma A. M. Bissi (1977-78, págs. 13-14) comenta la interpretación de estas figuras en el mundo tartésico.

12 Sin embargo, compárese con la tesis mantenida por A. PIGANIOL (1962), quién se apoya a su vez en V. BERCHEM, sobre un origen fenicio de la figura del Hércules romano, comparándolo con Kronos. Por tanto, si el origen de Hércules romano es fenicio, ¿no podría ser de origen fenicio o haber incluido lo fenicio en tipos icográficos itálicos?.

${ }^{13}$ Sin embargo, tanto algunas figurillas italianas como las francesas pueden enlazar con el fenómeno de contacto fericio en el mundo continental. S. CHIAPISI (1961, pág. 24) se refiere a una noticia dada por $F$. BENOIT sobre una estatuilla similar a la de Sciacca encontrada en los Alpes, que provendria de la ruta comercial que desde el Mediterráneo atravesaba los Alpes hacia el interior de Europa. Respecto a la posibilidad contacto entre los fenicios e Italia, hay que tener en cuenta la pervivencia del mundo fenicio en Cerdeña y Sicilia occidental hasta el siglo vı. Una remota posibilidad es que las figuras, en caso de que se inspirasen (o copiasen) realmente en una iconografía importada fenicia, podrian sustentarse sobre un fondo de creencias religiosas común, como se ha señalado antes al referirse a las afinidades entre los papeles de Marte (y Hércuies).

${ }_{14}$ A este respecto, y pese a lo dicho en la nota mencionando a Fürtwangler compárese sin embargo las hipótesis de SMITH, quien apunta un (idéntico) origen sirio-anatólico para las estatuas de Zeus Olímpico (Tonante). El tipo del "Smiting god" oriental se habría absorbido en Grecia, y, por tanto, existiría un antecedente, aunque no asociable a Hércules, frente a la clara y temprana definición del tipo (pese a sus variantes), en Italia. 
tea muchos obstáculos. J. Bayet (1926a) por ejemplo, cree que el Hércules romano es de origen griego, y para argumentar su postura presenta una serie de posibles vías de contacto por las que esta influencia habría podido alcanzar Roma. De igual manera, por tanto, podría haber llegado a otros puntos de la península. Una de esas vías de contactos apuntada por el investigador francés como de especial importancia es la etrusca. En su trabajo constata la importancia de la elaboración etrusca de Hércules, y pone de manifiesto incluso el origen chipriota de algún tipo ${ }^{15}$. También E. Richardson (1983, págs. 5, 27, etc.) señala como para otros bronces votivos de sus períodos "geométrico" y "orientalizante", el antecedente $u$ origen oriental es claro. $Y$ además, su temprana influencia sobre los etrusco. El papel que jugó la cultura etrusca como sintetizador y revitalizador ha sido puesto de manifiesto frecuentemente. No se puede olvidar precisamente aquí su actividad como intermediario entre lo fenicio y lo griego con el resto de la Península itálica.

Todas estas insinuaciones no esclarecen, sin embargo, la cuestión. Nos hemos limitado a apuntar un problema, señalar una posibilidad, y delimitar sus coherencias e incoherencias. Pero en cualquier caso, la búsqueda tendrá que darse dentro de las coordenadas antes expuestas: recepción de influencias en periodos anteriores, pervivencia enquistada de sustratos antiguos, llegados a través del influjo intermediterráneo, peso específico de lo indígena y de su interpretación, que debe valorarse separadamente en cada caso, y entrada final en escena de la cultura griega, que pasará a ser el cohesionador dominante.

${ }^{15} \mathrm{~J}$. BAYET (1926b. pp 35-44), observación que converge en cierto modo con la apreciación de A. M. BISI - ya mencionada anteriormente, en nota 2- sobre la importancia de los talleres de esa isla. Igualmente, indica la importancia de los elementos sardos como intermediarios en el trasvase de influencias entre fenicios y tirrenos. 


\section{BIBLIOGRAFÍA}

BALTY, J. Ch., 1961: "Note sur un type italique de l'Hercule Promachos", t. ap. del Bulletin des Musées Royaux d'Art et d'Histoire, serie 4, año 33. Bruselas.

-, 1962: «Degradations succesives d'un type d'Hercule italique», en Coll. Latomus, Vol. LVIII. Hommages à Albert Grenier.

- 1964: «A propos de quelques séries de bronzes italiques et du culte d'Hercule en Italie centrale. Problemes de orientations de recherches", t. ap. de Alumni XXXIV, sept. 1964. Bruselas.

BAYET, J., 1962a: Les origines de l'Hercule romain, Paris.

-, 1962b: Herclé. Etude crítique des principaux monuments relatifs à l'Hercule Étrusque. 153 pág., Paris.

BENOIT, F., 1959: Mars et Mercure. Nouvelles recherches sur l'interpretation gauloise des divinites romaines, Aix-en-Provence.

-, 1965: Recherches sur l'helenisation du Midi de la Gaule, Aix-enProvence.

Berchem, D. van, 1959-1960: "Hercule Melqart à l'Ara Maxima", Rendiconti Pontificia Academia Archeologia XXXII, págs. 61-68.

BISI, A. M., 1968: "Fenici o Micenei in Sicilia nella seconda metá del II millennio av. Cr.?", Atti e Memorie del Primo Congresso Internazionalle di Micenologia, 1157 ss. Roma.

-, 1977-78: “La diffusion du "Smiting God" syropalestinien dans le milieu phénicien d'Occident", Karthago XIX, pág. 5 ss.

BOUCHER, S., 1976: Recherches sur les bronces figurés de la Gaule preromaine et romaine. Bib. des Ecoles françaises d'Athenes et de Rome, fasc. 227. 
CHeValier, R., 1976: “Grecs, etrusques, celtes et cols des Alpes", L'Italie preromaine et la Rome republicaine. Melanges offerts à Jacques Heurgon. págs. 147-155.

CHIAPISI, S., 1961: "Melqart di Sciacca e la questione fenicia in Sicilia, Roma.

Collon, D., 1972: «The Smiting god. A Study of a Bronce in the Pomerance Collection in New York", Levant 4.

ColonNA, G., 1970: Bronze votivi umbro-savelli a figura umana. Florence.

Dussaud, R., 1946-48: «Melqart», Syria 25, pág. 205 ss.

DüRRBACH, F., 1900 (reimp. 1969): “Hercules», Dictionaire des Antiquites grecques et romaines, $111 / 1$, págs. 78-128.

FURTWÄNGLER, A., 1886-1890 (reimp. 1965): “Herakles", Lexicon der griechischen und römischen Mythologie, I. 2, col. 2135-2251.

Gavelie, R., 1967: "Autour de quelques bronzes figurés trouvés à Lvgdvnvm Convenarvm (Saint-Bertrand-de-Comminges, Haute-Garone)", Celticum 16, págs. 127 a 144.

Heurgon, J., 1961: La vie quotidienne chez les etrusques. Paris.

KIRK, G. S., 1974, ed. esp. 1984: La naturaleza de los mitos griegos, Barcelona.

NeGBI, O., 1976: Canaanite Gods in metal. An Archeological Study of Ancient Syro-Palestian Figurines, Tel Aviv.

PICARD, Ch., 1960: "Les voies terrestres du commerce hallstattien", Latomus, 19, págs. 409 ss.

PIGANIOL, A., 1962: «Les origines d'Hercule», en Coll. Latomus, vol. LVIII, Hommages à Albert Grenier.

Richardson, E., 1983: Etruscan Votive Bronzes. Geometric, Orientalizanting, Archaic. Mainz am Rheim.

SeEden, H., 1980: The Standing Armed Figurines in Levant, en la colección: Prähistorische Bronzefunde 1.1, Munich.

SMITH, R. H., 1962: "Near Eastern Forerunners of the Striding Zeus", Archaeology, 15, págs. 176-183.

THEVENOT, E., 1955: Sur les traces des Mars celtiques (entre Loire et Mont-Blanc), Brujas.

TUSA, V., 1973: "La stattuette fenicia del Museo Nazzionale di Palermo", Rivista di Studi Fenici l. 2, pág. 173 ss. 